\title{
Zloraba podjemne pogodbe - pogodbe o delu
}

UDK: 349.22:331.106

Nikolaj Abrahamsberg

Fakulteta za upravo, Univerza v Ljubliani

niko.abrahamsberg@fu.uni-li.si

\section{IZVLEČEK}

Avtor v prispevku opisuje razvoj podjemne pogodbe. Ugotavlja, da danes pri nas pogodbo zlorabljamo za zaposlovanje, kar ni dopustno. Glede na doseženo stopnjo razvoja delovno pravne zakonodaje ne moremo dopustiti dveh oblik zaposlovanja. Civilno pravna pogodba, to je podjemna pogodba oziroma pogodba 0 delu ne more biti pravna podlaga za zaposlovanje. Podjemna pogodba je namenjena podjemnikom (podjetnikom, gospodarskim družbam) za urejanje razmerij, pravic in obveznosti med podjemnikom in naročnikom nekega dela oziroma storitve. Enako kot pri gradbenih, prevoznih in drugih pogodbah, katerih vsebina je izvedba dela oziroma storitve. Fizična oseba kot izvajalec ne more skleniti podjemne pogodbe, če nima statusa podjetnika. Redke izjeme dovoliuje Zakon o preprečevanju dela in zaposlovanja na črno.

Ključne besede: podjemna pogodba, pogodba o delu, pogodba o zaposlitvi, podjemnik

$J E L: K 12$

\section{Uvod}

$\checkmark$ tej razpravi želimo pojasniti razlike med pogodbami, katerih vsebina je opravljanje določenega dela in se v praksi mnogokrat napačno uporabliajo.

$\checkmark$ času gospodarskih kriz se mnoga vprašanja izostrijo in zahtevajo ustrezno rešitev. $\vee$ praksi se srečujemo z mnogimi oblikami dela, ki so s posameznih vidikov ureditve sporne. Na eni strani imamo množico izjem, ki onemogočajo jasnost in preglednost ureditve, na drugi strani poskušamo stvari poenotiti ter poenostaviti in tako zahtevamo enako 
obdavčitev vseh vrst dela (pogodbeno delo, študentsko delo, delo upokojencev, avtorsko delo itd).

Prevelike obremenitve rednega dela zaposlenih s prispevki in davki silijo tako delodajalce kot tudi delavce $v$ iskanje cenejših in fleksibilnejših oblik zaposlovanja. Tako sta nam na področju dela zelo "koristili" avtorska pogodba, ki smo jo uporabljali tudi takrat, ko ni šlo za avtorsko delo, in podjemna pogodba. O zlorabi podjemne pogodbe govorimo takrat, ko delodajalec namesto sklenitve delovnega razmeria uporabi civilnopravno pogodbo in se s tem izogne zavezujočim določbam delovnopravne zakonodaje. Delodajalec se pojavlja kot naročnik dela oziroma storitve, čeprav sam $v$ resnici ni uporabnik izdelka oziroma storitve, ampak je uporabnik oziroma dejanski naročnik tretja oseba.

Fleksibilnosti zaposlovanja ne moremo reševati tako, da iščemo izhode $v$ civilnopravnih pogodbah. Tako je bila napaka, da smo iz zakona o delovnih razmeriih izločili oblike zaposlovanja za občasna oziroma začasna dela. Napako popravljamo z novim Zakonom o malem delu, čeprav le za kategorije brezposelnih, študentov in upokojencev. Primerneje bi bilo to sistemsko urediti v Zakonu o delovnih razmeriih in za vse oblike začasnega oziroma občasnega dela in za vse potencialne delojemalce.

Zlorabe obeh pogodb, tako avtorske pogodbe kot podjemne pogodbe (pogodbe o delu) ni primerno odpravljati z davčnimi instrumenti, ampak je treba sankcionirati nezakonito sklepanje teh pogodb. Sicer pa mora biti avtorsko delo nižje obdavčeno, če želimo spodbujati inovativnost in gospodarski razvoj in tudi kulturni dvig naroda. Po drugi strani je nedopustno obdavčiti delo glede na tip pogodbe, $v$ našem primeru podjemnih pogodb (pogodb o delu), ker s tem postavljamo pogodbenike $v$ neenakopraven, neustaven položaj. Po tej logiki bi morali obdavčiti delo po vseh pogodbah, katerih vsebina je opravljanje nekega dela (gradbene pogodbe, prevozne pogodbe itd.). Vprašati se moramo, ali je temeli za obdavčitev neka vrsta civilnopravne pogodbe ali plačilo za opravljeno delo $v$ delovnem razmerju.

Ker Obligacijski zakonik ne zahteva obličnosti za podjemne pogodbe, bi morali jasno definirati pogodbene stranke, da bi se izognili sivi ekonomiji. Neznano in neugotovliivo je število podjemnih pogodb, ki jih sklepajo fizične osebe, ki nimajo ustreznega statusa, to je statusa podjetnika. Po drugi strani pa ugotavljamo, da moramo po drugih 
predpisih prijaviti sklenitev pogodbe o delu na Zavodu za zaposlovanje. V preteklem letu je bilo prijavljenih preko 25.000 pogodb o delu. Očitno pa tu ne gre za podjemne pogodbe, ki jih ni treba registrirati, ampak za pogodbe o delu iz prejšnjega razveljavljenega Zakona o delovnih razmeriih. Vse navedeno kaže na nejasnosti in neustrezno ureditev področja.

Ni naš namen razpravljati o dajatvah in davkih, vendar menimo, da bi morala biti izplačila posamezniku za opravljeno delo enako obremenjena. Z našega vidika obravnave to tudi pomeni, da je lahko temeli izplačila za opravljeno delo, ki ga nekdo opravi $v$ imenu in za račun drugega, le pogodba o zaposlitvi, kakršna koli že: za nedoločen, določen, krajši ali daljši čas.

Posameznik, ki ni zaposlen (ni v delovnem razmeriu) lahko opravlja delo, le če izpolnjuje določene pogoje, sicer dela na črno.

Namen našega proučevanja je pokazati na nejasnost in neustreznost

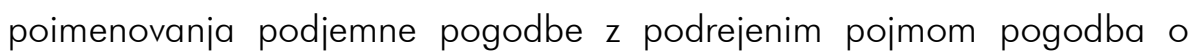
delu in posledično zlorabo podjemne pogodbe za sklepanje delovnih razmerii za občasna in začasna dela, ki jih je $v$ preteklosti urejal stari razveljavljeni Zakon o delovnih razmerih (1990). Nato opozoriti na pogodbene stranke, vsebino podjemne pogodbe in obliko pogodbe.

\section{Izvor in neustrezno poimenovanje pogodbe}

Izvirni greh neustrezne uporabe "pogodbe o delu" verjetno tiči že v samem Obligacijskem zakoniku (Ur. I. RS, št. 83/2001), ki neustrezno poimenuje oziroma enači pojma pogodba o delu in podjemna pogodba. XI. poglavje zakonika nosi naslov "Podjemna pogodba" in $v$ oklepaju "pogodba o delu", kar nas pripelje do zaključka, da gre za dve imeni za isto pogodbo. Zgodovinsko gledano gre $v$ resnici za dva različna tipa pogodb, ki imata isti izvor $v$ rimski locatio conductio.

Z navedbo $v$ oklepaju je zakonodajalec želel pojasniti pojem "podjem", ki v slovenskem jeziku ni pogosto v rabi. Vedeti moramo, da je beseda podjem izpeljana iz besede podjeten. V slovenskem pravopisu (Pravopis, 1950, str. 535) so iz besede "podjeten" izpeliane besede: podjetništvo, podjetje, podjetnik, podjem in podjemnik. Sinonim za "podjemno pogodbo" bi torej lahko bila "podjetniška pogodba" in ne pogodba o delu. Tako tudi Korošec za podjemno pogodbo uporablja pojem "delovršna ali podjetniška pogodba" (Korošec, 1948, str. 84) Ker 
Obligacijski zakonik obravnava mnogo podjetniških pogodb, ki so se razvile iz locatio conductio operis (pogodb, ki jih sklepajo podjetniki), je z navedbo $v$ oklepaju "pogodba o delu" želel le poudariti posebnost in razliko do drugih tovrstnih pogodb. Vendar $v$ svoji interpretativnosti zakonodajalec boli zavaja kot pojasnjuje.

Če bi želeli ostati pri pojmu delo, bi se pogodba morala poimenovati pogodba o izvršitvi (izvedbi) dela ali tudi delovršna pogodba, ne pa pogodba o delu. Zanimiva je tudi Cigojeva razlaga imena in utemeljitev pojma podjemniška pogodba: „V naše pravo je namesto izraza, ki ga uporablia ZOR (pogodba o delu), oziroma za slovensko uho okornega izraza delovršna pogodba, ki so ga prej uporabljali zlasti $v$ praksi, doktrina vpeljala izraz podjetniška pogodba, glede na to, da se z njo zaveže stranka, ki jo ODZ imenuje podjetnika. To ustreza tudi imenu, ki ga ima ta pogodba $\vee$ nekaterih drugih pravnih redih (contrat de entreprise francoskega prava). Vendar ima podjetje danes že prizvok institucije organiziranega trajnega gospodarskega delovanja. Podjemniški posel pa je lahko sklenjen samo za posamezen primer in ni pogoj tega posla, da bi bil podjemnik poklicni izvrševalec takšnih poslov. Gre torej za posamezen podjem. Spričo tega se mi zdi izraz podjemniška pogodba preciznejši« (Cigoi, 1998, str. 105).

"Pogodba o delu" oziroma pravilno podjemna pogodba je pogodba civilnega prava, s katero se podjemnik zavezuje opraviti določen podjem, to je opraviti določen posel, izdelati ali popraviti kakšno stvar, opraviti kakšno telesno ali umsko delo za naročnika (619. čl. OZ). Tu gre za najboli splošno podjetniško (gospodarsko) pogodbo, katere predmet je neko delo, ki ga podjemnik opravi za uporabnika, naročnika dela oziroma storitve. Cigoi podjemniško pogodbo uvršča med pogodbe o storitvah. Poleg nje med pogodbe o storitvah uvršča še naročilo oziroma mandatno pogodbo in shranjevalno pogodbo (Cigoj, 1998, str. 102).

Obligacijski zakonik poleg podjemne pogodbe pozna še vrsto posebnih pogodb, katerih predmet je določeno delo, podjem. Tako je na primer gradbena pogodba posebna podjemna pogodba, s katero se podjemnik zavezuje opraviti gradbena dela. Obligacijski zakonik v 649. členu to izrecno poudari: "Gradbena pogodba je podjemna pogodba ... Čeprav zakon $v$ drugih primerih posebej ne poudarja njihov podjemni (podjetniški) namen, pa $\vee$ teoriji med posebne podjemniške pogodbe poleg gradbene pogodbe uvrščajo še druge 
pogodbe, ki so se razvile iz pogodbe "locatio conductio operis". Tako Brank kot posebno vrsto pogodbe o delu šeje gradbeno in prevozno pogodbo (Brank, 1998, str. 129). Cigoi pa poleg teh še pogodbo o prenosu pisem in obvestil, založniško pogodbo in pogodbo o dajanju nasvetov (Cigoj, 1998, str. 117-142).

Kot ugotavlja Podgoršek, ureja zakon podjemno pogodbo v ožjem smislu. Iz te osnovne pogodbe so se $v$ gospodarskem prometu razvile in osamosvojile pogodbe, ki imajo poleg pravnih značilnosti osnovne podjemniške pogodbe tudi nekatere samosvoje poteze. Tako Obligacijski zakonik (ZOR) ureja na primer gradbeno pogodbo, prevozne pogodbe, Zakon o avtorskih in drugih pravicah pa avtorsko pogodbo. In dalje ugotavlja, da $v$ določenih primerih meja med osnovno in osamosvojenimi pogodbami ni očitna, tudi kadar ima predmet določene pogodbe posebnosti katere izmed naštetih osamosvojenih pogodb, gre lahko za podjemniško pogodbo $v$ ožjem smislu. Navaja tudi primer iz sodne prakse, ko je sodišče $v$ sporu med dvema gradbenima podjetjema štelo enostavna in manjša dela, izravnavo stropov in zidov, za predmet pogodbe o delu in ne za gradbeno pogodbo (Podgoršek, 1993, str. 189).

Da bi bolje razumeli in razlikovali podjemno pogodbo (pogodbo o delu) od drugih pogodb, je koristno pogledati njen zgodovinski izvor in razvoj. Podjemna pogodba ima svoj izvor v locatio conductio rimskega prava. Iz locatio conductio so se razvile naslednje pogodbe: najemna in zakupna pogodba - locatio conductio rei; službena ali pogodba o delu locatio conductio operorum in delovršna ali podjetniška pogodba locatio conductio operis (Korošec, 1948, str. 78).

Korošec pogodbo o delu pravilno enači s službeno pogodbo, torej drugače kot je pojem uporabljen danes. Pogodba o delu, locatio conductio operorum, službena pogodba je torej pogodba, s katero delavec prepusti delodajalcu $v$ določenem obsegu uporabljanje svoje delovne sile, zato pa od njega dobi plačilo $v$ denarju. Dalje tudi ugotavlja, da se službena pogodba $\vee$ rimskem sužnjeposestniškem gospodarstvu ni mogla razvijati, je pa pridobila večji pomen $\vee$ novem veku. Vprašanja, ki so z njo $v$ zvezi, pa daleč presegajo okvir zasebnega prava in spadajo v delovno pravo (Korošec, 1948, str. 83).

Kyovsky ugotavlja, da tudi gospodarski liberalizem 19. stoletja ni čutil potrebe, da bi s posebnimi predpisi urejal delovna razmerja, temveč se je posluževal pravnega instituta rimskega prava, in sicer locotio conductio 
operorum. Ta liberalistična misel, izposojena iz rimskega prava, je prišla do izraza $\vee$ Napoleonovem civilnem kodeksu in drugih zakonikih takratnega obdobja. Buržoazni pravni red je napravil majhno koncesijo s tem, da je na mesto romanistične službene pogodbe uvedel posebno novo obliko delovne pogodbe izven obligacijskega prava (Kyovsky, 1978, str. 179-180).

$\mathrm{Ni}$ namen te razprave analizirati razvoj locatio conductio operorum, rimske pogodbo o delu oziroma službene pogodbe, čeprav so $\mathrm{v}$ delovnopravni teoriii zanimive razprave o naravi te pogodbe. Po drugi strani pa ta pogodba, kot ugotavlja Cvetko, ni nikjer definirana (Cvetko, 2008, str. 67). Tuji pravni sistemi pogodbo o zaposlitvi urejajo ali v okviru delovnopravne zakonodaje (Francija, Rusija) ali pa kar $v$ civilnih zakonikih (Italija, Švica, Nemčija, Avstrija).

Zanimiva je ureditev $v$ italijanskem civilnem zakoniku, kjer je podjemna pogodba (Contratto di opera - 2222 čl. CC) tako kot tudi pogodba o zaposlitvi (Contratto di lavoro - 2097 čl. CC) urejena v peti knjigi, ki obravnava delo $v$ različnih organizacijskih oblikah medtem ko je podjemna pogodba obravnavana $\vee$ tretjem poglavju, ki govori o samostojnem delu. Vidimo, da za razliko od našega obligacijskega zakonika podjemna pogodba ni urejena $v$ četrti knjigi obligacii, kjer so urejene pogodbe: gradbena pogodba, prevozna pogodba in druge, ampak $v$ peti knjigi o delu. To kaže na drugačno sistemsko civilistično umestitev podjemne pogodbe, contratto di opera.

Pri nas je ta materija iz civilnega prava prešla v novo pravno panogo delovnega prava. Zato je bila pogodba o delu (ne podjemna pogodba), poleg pogodbe o zaposlitvi po Zakonu o delovnih razmeriih (Ur. I. RS, št. 14/1990) institut delovnega prava. Pogodba o delu se je uporabljala za začasna in občasna dela in je bilo delo glede na to časovno omejeno. Pogodba se je sklepala za začasna in občasna dela, ki so lahko trajala največ 60 dni v koledarskem letu oz. največ 8 ur na teden.

Delovna razmeria se urejajo s pogodbo o zaposlitvi. Vendar ker je Zakon o delovnih razmeriih $\vee 4$. členu preozko opredelil delovno razmerie, zlasti z omejitvijo, da se delo opravlia nepretrgoma, je vrsta del: zaposlitev za začasna dela, zaposlitev za občasna dela, ostala izven delovnopravne ureditve. Zato je praksa razumela, da se lahko razmerja, ki niso urejena z delovnopravno zakonodajo, urejajo s civilnopravnimi instituti in dalje izpeljala, da se lahko zaposluje tudi po civilnopravni

174 Uprava, letnik IX, 1/2011 
podjemni pogodbi (pogodbi o delu). Menimo, da to ni sprejemljivo in da moramo vse oblike zaposlovanja urejati v okviru delovnopravne ureditve. Tudi aktualne razprave o fleksibilnosti delovnega razmerja kažejo na to, da moramo na novo in drugače urediti vse vrste zaposlitve oziroma dela, zlasti to velja za razna krajša, občasna, začasna dela. Poskus v tej smeri je novi Zakon o malem delu.

Gospodarska družba oziroma podjetnik imata sicer možnost, da izvedbo določenih del prepustita drugi osebi, podjemniku, čeprav bi ta dela lahko opravili tudi pri niiju zaposleni delavci. Vendar gre tu za povsem različni pravni situaciji, različen pravni status izvajalca del in povsem različne pravne podlage oziroma različni pogodbi. Zato moramo razumeti, da sta "pogodba o delu" (/ocatio operorum), pravilno pogodba o zaposlitvi po delovnem pravu in "pogodba o delu", pravilno podjemna pogodba (locatio operis) po civilnem pravu dve povsem različni pogodbi, namenjeni urejanju različnih pravnih razmerij. Razlikujeta se po predmetu, obliki, vsebini pogodbe, po pogodbenih strankah in različnih pravnih posledicah sklenitve ene ali druge pogodbe.

Jasnost poimov je temeli učinkovitega pravnega reda in pravne varnosti. Vidimo, da je pojem "delo" večpomenski in pravno nejasen. Delo opravlja tako delavec, kot tudi podjemnik, vendar gre za povsem različna pravna razmerja. Zato danes poimenovanje neke civilne pogodbe, "pogodba o delu", ki zgodovinsko in po izvoru in glede na njen razvoj sodi $v$ delovno pravo, ni ustrezno. Ustvarja pojmovno nejasnost, nas zavaja in napeljuje na zaključek, da lahko razmerja pri delu urejamo tako po pravilih delovnega prava kot civilnega prava. Tudi v hrvaški teoriji, ki izhaja iz naše skupne pretekle ureditve $v$ Jugoslaviji, opozarjajo na jasno razlikovanje med pogodbama. V hrvaški pravni terminologijo uporabljajo pojem "ugovor o djelu" za locatio conductio operis - pri nas podjemna pogodba in "ugovor o radu" za locatio conducio operorum - pri nas pogodba o zaposlitvi (Vizner, 1971, str. 501).

V naši praksi se množično pojavljajo " pogodbe o delu", ki po vsebini niso podjemne pogodbe. $\vee$ teh primerih gre za prikrito delovno razmerje, kot ugotavlia Šetinc Tekavc, in bi morala ta razmerja biti predmet delovnopravne ureditve (Šetinc Tekavc, 2004, str. 14).

$\checkmark$ nadaljevanju bomo zaradi jasnosti opustili pojem pogodba o delu in bomo uporabljali pojem podjemna pogodba za civilnopravna razmerja in pogodba o zaposlitvi za delovnopravna razmerja. 


\section{Predmet pogodbe}

Predmet oziroma vsebina podjemne pogodbe je izvedba, izvršitev dela in ne samo delo. Delo lahko izvršijo podjemnik osebno ali pa pri njem zaposleni delavci. Bistven je delovni učinek, delovni rezultat in ne čas, količina dela. Plačan je rezultat dela in ne čas dela. Pri pogodbi o zaposlitvi pa gre za osebno delo delojemalca - delavca in dela ne more opravljati druga oseba. Plačano je njegovo delo po urah ali količinah, normah.

Pomemben je namen sklenitve pogodbe. Pri podjemni pogodbi naročnik pričakuje, da bo zanj in ne za nekoga drugega opravljena neka storitev. Kot poudarja zakon (619. čl. OZ), gre pri podjemni pogodbi za posel, kot je na primer izdelava stvari - sešiti obleko; popraviti stvar zamenjati motor $v$ pralnem stroju; telesno delo - varovanje prostorov; umsko delo - raziskovanje, analiza ravnanja potrošnikov na trgu, itd.

Pri podjemni pogodbi izvajalec delo opravlia v svojem imenu, za svoj račun in svoj riziko. Pri njem zaposleni delavec ni $v$ pravnem razmerju $z$ naročnikom dela. Do naročnika dela je le izjemoma lahko odškodninsko odgovoren, če je škodo povzročil namenoma (2. odst. 147. čl. OZ), sicer pa naročniku dela praviloma odgovarja delodajalec, $\vee$ tem primeru podjemnik (1. odst. 147. čl. OZ).

Kadar se izvajalec z nekom dogovarja, da bo ta namesto njega, ali v njegovem imenu opravil določeno delo, gre za dogovor o zaposlitvi in ne za podjem. Lahko pride sicer tudi do dogovora, da bo pri poslu sodeloval drug podizvajalec (subkontraktor). Vendar gre $v$ obeh primerih za novo pravno razmerje, novo pogodbo in nove pogodbene stranke. Naročnik posla iz podjemne pogodbe $v$ teh drugih pogodbah ni udeležen.

Poglejmo aktualen primer sklepanja podjemnih pogodb $v$ zdravstvu. Kdaj gre na področju zdravstva za podjemno pogodbo?

Če zdravstvena organizacija ali zasebni zdravnik - koncesionar (podjemnik) sklene z bolnikom, pacientom (naročnikom) dogovor o operaciji slepiča, je to podjemna pogodba.

Zdravstvena organizacija ali zasebni zdravnik (podjemnik) sta $\vee$ pravnem razmeriu s pacientom, bolnikom. Zdravnik, ki $v$ zdravstveni organizaciji opravlja delo, ni v pravnem razmeriu s pacientom. Zato tudi pacient ne more imeti odškodninskih zahtevkov zaradi nestrokovno opravljenega dela do njega, ampak odškodnino uveljavlja od zdravstvene

176 Uprava, letnik IX, 1/2011 
organizacije oziroma koncesionarja. Temelj za uveljavljanje odškodninskih zahtevkov naročnika, pacienta je podjemna pogodba.

Če se zdravnik (delavec) dogovori, da bo opravljal zdravstvene storitve (operacije slepičev) v zdravstveni organizaciii ali pri zasebniku, koncesionariu (delodajalcu), je to pogodba o zaposlitvi. $V$ tem primeru zdravnik (delavec) ni $v$ pravnem razmeriu z bolnikom, ampak ima pravno razmerje z zdravstveno organizacijo oziroma koncesionarjem.

$\mathrm{Na}$ primer, ko se zdravstvena organizacija ali koncesionar dogovarjata z zdravnikom, ki je zaposlen na Univerzitetnem kliničnem centru, da bo $v$ svojem prostem času pri njih oziroma za njih opravljal določeno delo - zdravstvene storitve, gre za dogovor o zaposlitvi. Torej bi morali skleniti pogodbo o zaposlitvi s krajšim delovnim časom (64. čl. Zakona o delovnih razmerijh, Ur. I. RS, št. 42/2002) in ne podjemne pogodbe (pogodbe o delu).

Civilnopravne podjemne pogodbe (pogodbe o delu), ki jih pogosto srečamo $v$ zdravstvu, torej po svoji vsebini niso podjemne pogodbe. Še huje, praksa je za svoje ravnanje našla podporo tudi $v$ podzakonskem aktu, v Uredbi o merilih za sklepanje podjemnih pogodb ali drugih pogodb civilnega prava za opravljanje zdravstvenih storitev $v$ mreži javne zdravstvene službe. Ta uredba je seveda $v$ nasprotju z Obligacijskim zakonikom in Zakonom o delovnih razmeriih.

Seveda taki primeri niso le $v$ zdravstvu ampak tudi zelo pogosto $v$ izobraževalni dejavnosti, zlasti visokem šolstvu, v raziskovalni dejavnosti, v kulturi in drugie.

$\checkmark$ zvezi s pogodbami o zaposlitvi s krajšim delovnim časom velja opozoriti na omejitve, ki jih določa 146. člen ZDR. Delavec, ki že dela poln delovni čas, sme skleniti pogodbo o zaposlitvi le s soglasjem delodajalca pri katerem dela polni delovni čas in če gre za deficitarne poklice ali za opravljanje vzgojno-izobraževalnih, kulturno umetniških in raziskovalnih del. Delavec lahko opravlja tako delo največ osem ur na teden. Teh omejitev pa ni, če gre za delavca, ki dela krajši delovni čas in sme skleniti več takšnih razmerii, da bi tako dosegel polni delovni čas (1.odst. 65. čl. ZDR). Soglasje delodajalca $\vee$ tem drugem primeru ni potrebno. Lahko pa gre za omejitve, ki so vezane na lojalnost delavca do svojega delodajalca in s tem povezano konkurenčno klavzulo. To velja tudi $v$ primeru podjemne pogodbe. 
Pogodba o zaposlitvi za polni ali krajši delovni čas se lahko sklepa tudi za določen čas in tako bi lahko rešili tudi primere občasnih in začasnih del. Utemeljeno bi lahko ugovarjali, da v primerih občasnih in začasnih del niso podani vsi elemente delovnega razmerja, ki jih določa 4. člen ZDR. Res je, pri teh delih praviloma ni mogoče ugotoviti nepretrganosti dela in tudi ne vključenosti $v$ organiziran delovni proces. $V$ tem vidimo pomanjkliivost oziroma togost definicije delovnega razmerja, ki bi jo veljalo spremeniti.

Zato Šetinc Tekavc ugotavlja, da v primeru, ko elementi delovnega razmerja niso podani kumulativno, zainteresiranima strankama ni treba skleniti pogodbe o zaposlitvi kot ugodnejše oblike za delavca, ampak sta stranki prosti, da skleneta za opravljanje določenega dela civilnopravno pogodbo, torej lahko tudi podjemno pogodbo (Šetinc Tekavc, 2004, str. 14). Podjemna pogodba da, vendar le, če so izpolnjeni statusnopravni pogoji izvajalca del, sklenitelja pogodbe (podjemnika). "Delavec" teh pogojev praviloma ne izpolnjuje, o čemer kasneje.

Skleniti neko inominatno civilno pogodbo o zaposlitvi, o delu, pa menimo, ni dopustno. Urejanje delovnih razmerij je pri nas, kot $v$ nekaterih drugih tujih ureditvah, izvzeto iz civilnega prava in proste volje pogodbenih strank. Tako Ustava $\vee 66$. členu zagotavlja zakonsko varstvo dela. Urejanje delovnih razmerij je zato vezano na obvezujoče določbe zakona. Kot ugotavlja Vodovnik, država to varstvo zagotavlja na različne načine, zlasti pa tako, da je z zavezujočimi (kogentnimi) predpisi omejila prostost strank pri sklepanju pogodbe o zaposlitvi (Vodovnik, 2006, str. 21). Tako ni mogoče "dela" urejati ali delovnopravno ali civilnopravno po prosti volji pogodbenih strank. Glede na že doseženo stopnjo delovnopravnega varstva delavcev, bi to pomenilo korak nazai $v$ urejanju delovnih razmerij. Vsa delovna razmeria morajo ostati $v$ domeni delovnega prava.

\section{Oblika pogodbe in pogodbene stranke}

Podjemna pogodba je konsenzualna, brezoblična pogodba. Pogodba je sklenjena, ko se izjavi pogodbenih strank ujemata. Drugače je pri pogodbi o zaposlitvi, kjer je oblika predpisana. Pogodba o zaposlitvi se sklene v pisni obliki (1. odst. 15. čl. ZDR), čeprav neizpolnitev te zahteve ne vpliva na obstoj in veljavnost pogodbe o zaposlitvi (4. odst.15. čl. ZDR). Težko si sicer predstavljamo obstoj in veljavnost pogodbe, ki je ni. Lahko si predstavljamo obstoj delovnega razmeria, 
Čeprav pisna pogodba ni bila sklenjena, obstoj in vsebino pogodbenega razmerja pa bo treba šele dokazati. Glede na našo sedanjo nezakonito prakso sklepanja podjemnih pogodb (pogodb o delu) bo delodajalec imel izgovor, da je sklenil pogodbo o delu, ki je lahko ustna, ker če bi z delavcem želel skleniti delovno razmerje, bi sklenil pisno pogodbo o zaposlitvi.

Kot navaja Šetinc Tekavc "V našem pravu nikjer ni predvidena registracija ali potrditev pogodbe o delu (podjemne pogodbe), še posebej zato, ker gre za neformalno pogodbo, ki je lahko sklenjena tudi ustno." (Šetinc Tekavc 2004, str. 14). Očitno veljavna praksa prijave pogodbe o delu Zavodu za zaposlovanje kaže na neko drugo pogodbo o delu, ki je dejansko pogodba o zaposlitvi za občasno oziroma začasno delo in ne podjemna pogodba civilnega prava.

Drugo pomembno vprašanje je, kdo so lahko pogodbene stranke. Ko jih zakonodajalec poimenuje: pri pogodbi o zaposlitvi delodajalec in delavec oziroma pri podjemni pogodbi podjemnik in naročnik, jim s tem daje tudi ustrezno vsebinsko razliko. Zato ni mogoče enostavno teh pojmov enačiti, kot na primer Rajšter Vranovič podjemnika enači z delavcem in naročnika z delodajalcem (Rajšter Vranovič, 2003, str. 13).

Tako se zastavi vprašanje ali lahko delodajalec s svojim delavcem, s katerim ima sklenjeno pogodbo o zaposlitvi, sklene še podjemno pogodbo. Na primer s šoferjem, ki dela polni delovni čas, sklene delodajalec še podjemno pogodbo o servisiranju službenih vozil $v$ njegovem prostem času $v$ soboto in nedeljo. Podobni primeri v praksi niso redki. In drugo vprašanje, ali je lahko vsaka fizična ali pravna oseba podjemnik.

Z delovnopravnega vidika smo s sklenitvijo takšne podjemne pogodbe obšli z zakonom zajamčeno pravico delavca, v konkretnem primeru pravico do tedenskega počitka. Ker gre za pravico delavca bi lahko rekli, da se ji delavec lahko odpove in po tej logiki bi se delavec lahko "prostovolino" odpovedal vsaki pravici, ki je delovno pravno varovana. Delodajalec pa se je $v$ tem primeru izognil prispevkom, ki se plačujejo iz delovnega razmeria. To seveda ni dopustno.

Odgovor na drugo vprašanje je pomembnejši. $V$ našem pravnem sistemu imamo statusno pravne oblike predpisane. Kdor želi opravljati neko pridobitno dejavnost, se mora ustrezno statusno organizirati. Zakon - gospodarskih družbah ponuja obliko samostojnega podjetnika ali 
katero od oblik gospodarskih družb. Kdor opravlja delo in ni organiziran v eni od predpisanih statusnih oblik, dela na črno. Če posameznik opravlja dejavnost oziroma delo in ni vpisan ali priglašen kot to zahteva Zakon o preprečevanju dela in zaposlovanja na črno ali drugi zakon (4. al. 1. odst. 3. čl. ZPDZC, Ur. I. RS, št. 12/2007), dela na črno. Delo na črno je prepovedano (2. odst. 3. čl. ZPDZC).

Obravnavani zakon našteva tudi izjeme, ko določenih del ne štejemo za delo na črno, to so: medseboina sosedska pomoč, delo v lastni režiji, nujno delo, humanitarno delo in osebno delo (1. odst. 7. čl. ZPDZC). Prav tako ne gre za zaposlovanje na črno, če gre za kratkotrajno oziroma malo delo (2. odst. 7. čl. ZPDZC). Po veljavnem zakonu moramo osebno dopolnilno delo in kratkotrajno delo prijaviti upravni enoti (12. čl. in 12a. čl. ZPDZC). Ko gre za malo delo, mora delodajalec skleniti pogodbo o mali zaposlitvi (12b. čl. ZPDZC) in ne mogoče podjemno pogodbo.

Obravnavani primer šoferja - mehanika ne moremo uvrstiti pod noben primer obravnavanih izjem po Zakonu o preprečevanju dela in zaposlovanja na črno. Torej v soboto in nedeljo dela na črno. Ostane sicer možnost, da bi takšno delo opravljal, če ima status podjetnika in je vpisan $v$ poslovni register.

Tako smo pri temelinem vprašanju, kdo so pogodbene stranke pri podjemni pogodbi. Iz definicije podjemne pogodbe izhaja, da sta to podjemnik in naročnik. Naročnik je lahko katerakoli fizična ali pravna oseba, ki je naročila določen posel in se zavezala, da bo opravljeno delo plačala. Naročnik je dolžan prevzeti delo, ki je bilo izvršeno po določilih pogodbe in pravilih posla (641. čl. OZ).

Druga pogodbena stranka pa ni kdorkoli. Obligacijski zakon drugo pogodbeno stranko konkretizira. Pri podjemni pogodbi je to podjemnik, pri gradbeni pogodbi izvajalec, pri prevozni pogodbi prevoznik, pri skladiščni pogodbi skladiščnik, itd. Če se zatečemo $k$ besedni razlagi pojma podjemnik, bomo ugotovili, da Slovar slovenskega knjižnega jezika (Slovar, 1994, str. 869) te besede ne pozna več, pozna pa prevoznika, izvajalca, skladiščnika. Podjemnika naj bi torej nadomestila beseda podjetnik glede nato, da sta se besedi podjem in tudi podjemnik razvili iz pojma "podjeten" Zato ne bi bilo nič narobe, če bi tudi zakonodajalec uporabil pojem podjetnik. Pod splošnim pojmom podjetnik oziroma podjetje razumemo v ekonomskem smislu vsakogar, ki opravlja pridobitno 
dejavnost na trgu torej tako samostojnega podjetnika kot tudi vse oblike gospodarskih družb.

Na današni stopnji razvoja in urejenosti pravno organizacijskih oblik $\checkmark$ katerih izvajamo dejavnost, ne moremo pristati na liberalistične poglede z začetkov kapitalizma, ko je lahko vsakdo opravljal pridobitno dejavnost. Če so že $v$ srednjem veku imeli jasna pravila o statusu obrtnikov in trgovcev in obveznost vpisa $v$ stanovske registre kot pogoj za opravljanje dejavnosti, je danes $v$ urejeni pravni državi to še toliko boli pomembno.

Da bi lahko opravljali dejavnost, moramo izpolnjevati splošne in posebne pogoje. Pod splošnimi pogoji razumemo ustrezno statusno obliko organiziranja in dolžnost vpisa $v$ ustrezni register. $V$ skladu $z$ načelom numerus clausus nam pravni red ponuja mogoče oblike organiziranja. Zakon o gospodarskih družbah nam ponuja statusno pravne oblike samostojnega podjetnika, osebne in kapitalske družbe in gospodarska interesna združenja. Posebni zakoni urejajo položaj samostojnih intelektualnih poklicev. Zastareli Zakon o zavodih in več posebnih zakonov urejajo obliko izvajanja nepridobitnih dejavnosti.

Podjetnik lahko prične opravljati dejavnost, ko je pri AJPES vpisan v Poslovni register Slovenije (1. odst. 74. čl. ZGD). Gospodarska družba lahko začne opravljati dejavnost, ko je vpisana v sodni register (6. odst. 6. čl. ZGD).

Glede na povedano lahko torej zaključimo, da je podjemnik kot pogodbena stranka lahko le oseba, ki izpolnjuje statusne pogoje, sicer gre za opravljanje dela na črno.

Za izvajanje dejavnosti so pomembni tudi posebni pogoji, ki za naročnika pomenijo zagotovilo, da izvajalec, podjetnik, gospodarska družba izpolnjuje osnovne pogoje za izvajanje določene dejavnosti. To so tehnični, sanitarni, higienski, kadrovski in drugi pogoji, ki se glede na vrsto dejavnosti razlikujejo. Neizpolnjevanje teh pogojev pomeni kršitev in $\checkmark$ skrajnem primeru tudi prepoved opravljanja dejavnosti. $\vee$ nekaterih izjemnih primerih se izpolnjevanje teh pogojev preverja celo pred pričetkom opravljanja dejavnosti. $V$ teh primerih pristojni državni organ pred pričetkom opravljanja dejavnosti izda ugotovitveno odločbo o izpolnjevanju pogojev.

Sedanja zakonodajna praksa, ki zaradi odpravljanja "administrativnih ovir" opušča oziroma minimalizira posebne pogoje, po našem mnenju 
ni pravilna in je škodljiva za uporabnike oziroma potrošnike. Strinjamo se, da praviloma administrativno preverjanje posebnih pogojev pred ustanovitvijo ni potrebno, kar pa ne pomeni, da posebnih pogojev ne bi določili. Nespoštovanje teh pogojev mora biti sankcionirano.

\section{Sklep}

$\checkmark$ skrbi za pravno državo in učinkovit pravni red je temeljno, da so nam pravni pojmi, pravni instituti in pravna razmerja jasni.

Vsak pravni pojem naj bi imel enak in enoznačen pomen v vsakem zakonu ali podzakonskem aktu. Zato sedanje prepisovanje oziroma zgledovanje po evropski nomotehniki pojasnjevanja pomena pojmov $v$ evropskih pravnih aktih za nacionalni pravni red ni sprejemljivo. $V$ Evropski uniji je tak nomotehnični pristop razumljiv in nujen zaradi različnih pravnih redov članic. $V$ nacionalni zakonodaji pa to ni sprejemliivo, ni potrebno in je nevarno, ker ustvarjamo negotovost in nejasnost pojmov, če je pojem $v$ enem zakonu opredeljen tako, v drugem pa drugače. Na primer pojem "podjetje" ima v naših zakonih nedopustno različen pomen, ali povezavo družb $\vee$ Zakonu o gospodarskih družba imenujemo "koncern" $\vee$ Zakonu o bančništvu pa "bančna skupina", namesto bančni koncern, itd. Pojem, ki je definiran v ustavi ali v splošnem predpisu (lex generalis) mora biti enako in dosledno uporablien $\vee$ vseh posebnih predpisih (lex specialis) in drugih podzakonskih aktih. Tako se gradi pravni jezik in zagotavlja pravna jasnost in posledično varnost.

Zato $v$ našem primeru ni nobene potrebe, da bi za neko pogodbo uporabili dva različna pojma oziroma imeni. Zato bi bilo korektno, da v Obligacijskem zakoniku opustimo ime "pogodba o delu" in ostanemo samo pri enem pojmu to je pri "podjemni pogodbi". In še posebej glede na opisani zgodovinski razvoj te pogodbe.

Dalje menimo, da je razvoj delovnih razmerii na taki stopnii, da je pravilno vse oblike zaposlovanja urejati znotraj delovno pravne ureditve. Jasno je treba tudi povedati, da zaposlovanje na podlagi civilnopravnih razmerii, civilnih pogodb ni dopustno. Tako ni dopustno zlorabljati podjemne pogodbe za urejanje razmerij pri zaposlovanju delavcev za občasna oziroma začasna dela. Kot smo ugotovili, število teh pogodb ni majhno in kar je najslabše, sistem jih dopušča. Zato je treba dodelati delovno zakonodajo, ki mora opredeliti vse možne oblike zaposlitev in opustiti sedanjo togo ureditev. Sporni Zakon o malem delu poskuša 
praznino, ki je nastala zaradi neurejenosti zaposlovanja za občasna in začasna dela urediti, vendar nesistemsko in le za določene skupine oseb.

Redke izjeme, ko ni treba skleniti pogodbe o zaposlitvi oziroma ni treba biti organiziran kot podjetnik ali gospodarska družba, da bi lahko sklenili podjemno pogodbo, določa Zakon o preprečevanju zaposlovanja in dela na črno.

Dalje menimo, da je $v$ urejenem gospodarstvu nujno spoštovati pravila in pogoje opravljanja dejavnosti. Prvi pogoj opravljanja dejavnosti je ustrezna statusna organiziranost, to pomeni, da moramo biti organizirani kot podjetnik ali kot gospodarska družba in zaradi pravne varnosti moramo biti vpisani $v$ ustrezni register (poslovni register, sodni register, register svobodnih poklicev). Dopuščanje dela na črno in zatiskanje oči pred tem množičnim pojavom z izgovorom, da blažimo socialne stiske, ni dopustno in je nepošteno do tistih, ki svoje obveznosti spoštujejo.

Mag. Nikolaj Abrahamsberg je magisterij s področja delovnega, socialnega in statusnega prava in naziv magistra pravnih znanosti pridobil na Pravni fakulteti Univerze v Ljubljani. Izpopolnjeval se je na univerzah v Trstu, Trentu in Liverpoolu. Bil je dekan in prodekan Višje upravne šole oziroma Visoke upravne šole. Predaval je na Fakulteti za upravo $v$ Ljubliani, Fakulteti za management v Kopru in na Turistici v Portorožu. Predaval je statusno pravo na Fakulteti za upravo v Ljubljani, gospodarsko pravo na Fakulteti za management $v$ Kopru in pravne predpise v turizmu na Turistici v Portorožu. Predaval je tudi delovno pravo na Višji upravni šoli v Ljubliani. 


\section{Literatura in viri}

- Brank, J. (1998). Obligacijsko pravo. Koper: Fakulteta za management.

- Cigoj, S. ( 1998). Institucije obligacij. Ljubliana: ČZ Uradni list.

- Cretko, A. et al. (2008). Zakon o delovnih razmeriih s komentarjem. Ljubljana: Gospodarski vestnik.

- Korošec, V. (1948). Rimsko obligacijsko pravo. Ljubliana: Pravna fakulteta.

- Kyovsky, R. (1978). Delovno pravo. Ljubljana: Pravna fakulteta.

- Podgoršek, B. et al. (1993). Gospodarske pogodbe. Ljubljana: Gospodarski vestnik.

- Rajšter Vranovič, B. ( 2002). Pogodba o delu - pred in po 1. januarju 2003. Pravna praksa (40). Ljubljana: GV Založba.

- Šetinc Tekavc, M. (2004). Pogodba o delu. Pravna praksa (13). Ljubljana: GV Založba.

- Vizner, B., Kapor, V. \& Carić, S. (1971). Ugovori građanskog i privrednog prava. Rijeka.

- Vodovnik, Z. (2006). Poglavia iz delovnega in socialnega prava. Ljubliana: Fakulteta za upravo.

- Obligacijski zakonik, Ur. I. RS, št. 83/2001

- Zakon o gospodarskih družbah, Ur. I. RS, št. 42/2006, UPB 65/2009

- Zakon o delovnih razmeriih, Ur. I. RS, št. 14/1990

- Zakon o delovnih razmerijh, Ur. I. RS, št. 42/2002

- Zakon o preprečevanju dela in zaposlovanja na črno, Ur. I. RS, št. 12/200

- Uredba o merilih za sklepanje podjemnih pogodb ali drugih pogodb civilnega prava za opravljanje zdravstvenih storitev v mreži javne zdravstvene službe, Ur. I. RS, št. 36/2009

- Codice Civile. GU št. 79/1942. http//www.jus.unitn.it/cardozo/obiter_dictum/codciv. Zadnja uskladitev CC 2000

- Pravopis. (1950). Slovenski pravopis. Ljubljana: SAZU.

- Slovar. (1994). Slovar slovenskega knjižnega jezika. Ljubljana: DZS. 
SUMMARY

\section{THE ABUSE OF "WORK CONTRACT"}

Keywords: work contract, service contract, employment contract, contractor

In the article, the author describes development of work contract (service contract) that has evolved from the Roman "locatio conductio operis" and compares it with the employment contract, which has evolved from the Roman "locatio conductio operorum". The author points out the inappropriate use of term locatio conductio operis in the Slovene Civil Code, which uses two different terms for this contract: "work contract" (meaning service contract) and "contract of work" (meaning employment contract). This misuse of legal terms diminishes the fundamental difference between the two types of contract that belong to different fields of law. The "contract of work" (employment contract) belongs to labour law; in fact this contract has been regulated in Labour Relations Act until 2002, whilst the "work contract" (service contract) falls within the civil law of the contract. Since the Labour Relations Act defined the elements of the employment contract ("contract of work") too narrowly and did not cover occasional and temporary jobs, the practice used the contract work improperly.

The author argues that, starting from highly developed labour legislation in Slovenia, we can not allow two forms of employment. The civil "work contract" (in sense of locatio conductio operis) can not be the legal basis for employment relationship. Work contract is intended for entrepreneurs, companies and other persons who are in business in their own account. Service contract (in Slovene legislation improperly called contract of work or work contract) is aimed to regulate the relationships (rights and obligations) between those entrepreneurs, companies and other persons and the "buyers" of their service and is, in this sense, very similar to the transport contract, contract of construction or any other contract, the content of which is the performance of a particular work or service. An individual person is unable to conclude a service contract, unless she/he is an entrepreneur, and exceptions from this rule are rarely permitted. The controversial proposal of Act on small work (still in the procedure) is trying to fill the described gap regarding the occasional and 
temporary work, but just for certain groups of people and in a nonsystematic and improper way.

Service contract is the most common contract in civil law, by which one contractor is bound to carry out a certain job, like build or repair something or perform a certain physical or mental work for the other contractor. Other civil law contracts like transport contract, contract of construction and some others emerged (developed) from service contract. The subject of all these contracts is performance of a certain job, but not an employment relationship. This job can be performed by an entrepreneur himself or by workers employed by him. The relationship between the service provider and the buyer of the service, which is regulated by service contract, is very different from the relationship between the provider of the service and his employees, which is regulated in the employment contract. Those employees are in no legal relationship with the buyer of the service.

An important difference between the contract work and the employment contract is in the formalities that are prescribed for the latter. The employment contract must be concluded in written form, while no formalities are required for the work contract. However, in practice there is still a requirement to notify the work contracts to the State Employment office, even if this was regulated in the repealed Labour Relations Act (1990). In the last nine months of 2010 , there were more than 20.000 notifications of such work.

Regarding the service contract and other business contracts like construction contract, transport contract and similar, the important question is who are the contracting parties. It is undisputed that the buyer of the service can be any legal or natural person. On the other hand, the contractor that provides the service can not be anyone. A business activity can be carried out only by persons that meet general and specific requirements. Under general requirements we understand the proper form of a conducting a business and the duty of registration in the business register. In accordance with the principle of numerus clausus, the law offers a variety of possible forms of organization. The Companies Act regulates: private entrepreneur, private companies, joint stock companies and economic interest groups. Specific laws are provided for conduction of independent intellectual professions. All of the mentioned can start performing their business after registering in the business register. From 
the legal point of view, it is clear that the persons who are not organised in one of the mentioned forms, are performing an undeclared work (some exceptions are provided in the Act on prohibition on undeclared work and in the Proposal of Act on small work).

In conclusion the author points out the importance of clarity and precision of legal concepts. He therefore proposes that the "contract of work" (meaning employment contract) should be abolished (cancelled) from the Civil Code, and only the "contract work" (meaning service contract) is to be regulated within the Civil Code. The duality of descriptions of the same contract creates only unnecessary confusion and misinterpretation.

In the end the author argues that regarding the level of development of working relationships in Slovenia, it is only suitable and correct to regulate all forms of employment contract within the labour law. It has to be clearly stated that employment relationships should not be concluded by other civil law contracts (like service contract). The supplementing labour legislation should define all possible forms of employment and abandon the current rigid regulations. 